\title{
COMMON INJURIES IN ATHLETES' KNEE: EXPERIENCE OF A SPECIALIZED CENTER
}

\author{
Alexandre Pedro Nicolini, ${ }^{1}$ Rogério Teixeira de Carvalho, ${ }^{1}$ Marcelo Mitsuro Matsuda,${ }^{1}$ Jorge Sayum Filho, ${ }^{1}$ Moisés Cohen ${ }^{2}$
}

\section{ABSTRACT}

Objective: The present cross-sectional study aims to identify the most common knee injuries in athletes cared at a Specialized Outpatient Clinics. Method: Analysis of patients cared at the Knee Outpatient Clinics of a Sports Trauma Center, divided by gender, age and diagnosed injury. Results: Initially 440 patients were divided into 33 types of sports; after excluding the less statistically significant practices, nine sports remained. The most frequently performed sports were football with almost $50 \%$ of total patients presenting anterior cruciate ligament $(A C L)$ injury, and road runs with great frequency of meniscal injury. There was no correlation of the disorder with the type of sports performed but a correlation was found with patient's age/gender. Conclusion: The complete ACL rupture was the most common injury found in football, basketball and volleyball players, followed by meniscal injury in street runners. Level of Evidence IV, Study Transversal.

Keywords: Knee injuries. Sports. Epidemiology. Soccer. Athletes. Musculoskeletal system/injuries.

Citation: Nicolini AP, Carvalho RT, Matsuda MM, Sayum Filho J, Cohen M. Common injuries in athletes' knee: experience of a specialized center. Acta Ortop Bras. [online]. 2014;22(3):127-31. Available from URL: http://www.scielo.br/aob.

\section{INTRODUÇÃO}

Musculoskeletal injuries are common in sports practice and correspond to $80 \%$ of lesions in sports. ${ }^{1-4}$ Joint injuries, especially on the knee, have significantly increased due to increase of the number of people who practice physical activities, both professionally and recreationally. In addition, starting sports activities has happened at early ages, with training request and increasing levels of competitiveness, sometimes devoid of appropriate technical supervision. ${ }^{1,5.6}$

Sports injuries can be defined in numerous ways: injuries that lead to stopping practice or competition, decreased activity, and need for medical care. ${ }^{5,6}$ The National Athletic Injury Reporting System (NAIRS) from U.S.A. divides lesions into the following categories: non-reportable, the athlete does not interrupt activities; minor, losing of 1-7 days; moderate, 8 to 21 days; major, over 21 days loss and severe injury, resulting in permanent disability. ${ }^{7,8}$ Some other factors may determine the severity of the injury, its nature, duration of treatment, absence from school and costs involved. This number of musculoskeletal injuries comprise the majority of bruises, light sprains, and muscle injuries (about 54\%) which compromises sports practice for a brief period of tyme. ${ }^{9}$ These correspond to non-reportable injuries, lighter, smaller and in a smaller proportion, moderate ones. The lower limb is most commonly affected, due to the overhead imposed in sports that involve running and jumping, in which the force on the knees can reach up to 10 times the body weight; other important factors would be the change of direction, as in football, and physical contact between participants. ${ }^{8,10}$ Approximately $90 \%$ of sports injuries are located in the hip, thigh, knee, leg, ankle and foot. $8,11,12$

There are few Brazilian studies that assess the epidemiology of knee injuries in practice of various sports, inversely to what is observed in the international literature. ${ }^{13-22}$

The aim of this study is to conduct a cross-sectional analysis of the most common orthopedic injuries in the knee found in athletes of different sports categories, who were seen in an outpatient's ward of a specialized center. Since it is a referral center, the majority of patients seen have moderate, severe and even serious injuries, according to the NAIRS classification, which prevent athletes from physical activity for a prolonged period. This information may assist in the prevention, diagnosis and treatment of knee injuries in sports practice, professional or recreational, and in order to establish a profile of that patient, and the specialized service driven to sportsmen.

All the authors declare that there is no potential conflict of interest referring to this article.

\footnotetext{
1. Centro de Traumato-Ortopedia do Esporte (CETE), Department of Orthopedics and Traumatology, Escola Paulista de Medicina, Universidade Federal de São Paulo (Unifesp), São Paulo, SP, Brazil.

2. Department of Orthopedics and Traumatology, Universidade Federal de São Paulo (Unifesp), São Paulo, SP, Brazil.

Work developed at Centro de Traumatologia do Esporte, Department of Orthopedic and Traumatology, Universidade Federal de São Paulo (Unifesp), São Paulo, Brazil. Correspondence: Rua Estado de Israel, 636, Vila Clementino, 04022-001 - São Paulo, SP, Brazil. apnicolini@uol.com.br
} 


\section{MATERIALS AND METHODS}

After approval by the Institution's Ethics Research Committee, the records of patients seen at the outpatient clinic specialized in knee surgery a Specialized Center for Sports Traumatology from January 2008 to September 2009 were analyzed.

Inclusion criteria were patients diagnosed with knee injury, caused or symptomatic during sports practice, which prevented the athlete/patient from training for a variable period of time.

Exclusion criteria were: patients who were not athletes, who had not confirmed and signed diagnosis (either clinical or by imaging) and finally, those who had some injury not related to sports, for example, patients with tibial plateau fractures caused by traffic accidents.

We obtained a total of 440 patients included in the study, that were analyzed according to: age, gender, sport practiced, and diagnosis (knee injury), as a unique injury or associated with others. The diagnosis was made by clinical examination and imaging by an experienced examiner, specialized in knee surgery; analysis of medical records were performed by a single orthopedic surgeon.

From this data collection a statistical analysis was performed, with patients being divided by sports category and subsequent percentage division of the lesions, mean age of practitioners and division by gender. We obtained a total of 33 sports categories and lesions consisted mostly of chronic injuries that slowed or made impossible sports practice. The mean age was 28.25 years old (range 18-47) and the division by gender for the whole sample was $28 \%$ female and $72 \%$ male.

On statistical analysis, categories with less than 10 practitioners (without statistical importance) were excluded and the remaining categories (nine sports categories) were analyzed, comparing mean age, gender and most prevalent injuries, trying to establish correlations between them. For this analysis, the chi-square test and Fisher exact test were used.

\section{RESULTS}

After cross-examination, we reached a total of 440 patients divided into 33 sports categories. We can observe the distribution of athlete categories in Figure 1.

After division by category, patients were analyzed regarding gender, mean age and diagnosed injury. The main lesions found are shown in Table 1.

As for all patients, mean age and gender data obtained are reported in Table 2.

The least common diagnoses were: osteoarthritis, Osgood-Schlater osteochondritis, chondral injury, medial collateral ligament injury, lateral collateral ligament injury, and posterior cruciate ligament injury.

We can still cite as findings: ischiotibial tendinopathy, popliteal tendinopathy, iliotibial tract syndrome, goose foot tendinopathy, avulsion fracture of the tibial-tuberosity (patient aged 15 years old), contusion, muscle injury, synovial plica, tibial plateau fracture, quadriceps tendinopathy, and finally, stress fracture of the patella.

Among combined lesions, we observed that $34.7 \%$ of ACL injuries were associated to meniscal injury, $6.2 \%$ were associated with MCL injury, $2.4 \%$ association with PCL injury and $3.7 \%$ associated with chondral injury. Regarding meniscal injuries,

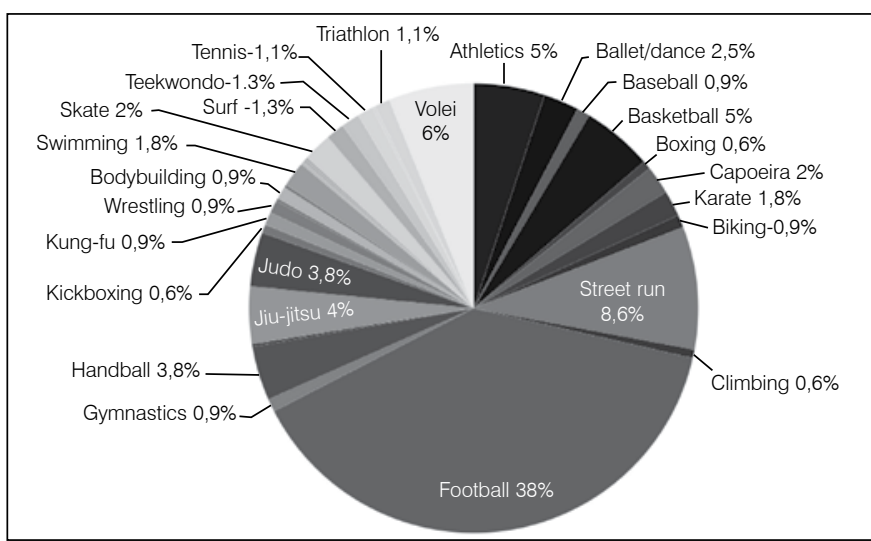

Figure 1. Division according to modalities practiced.

Table 1. Sports categories practiced versus most frequent injuries.

\begin{tabular}{|c|c|c|c|c|c|}
\hline $\begin{array}{c}\text { Sports category/ } \\
\text { injury }\end{array}$ & $\begin{array}{l}\text { Meniscal } \\
\text { injury }\end{array}$ & LCA & $\begin{array}{l}\text { Patellar } \\
\text { instability }\end{array}$ & $\begin{array}{c}\text { Patellar } \\
\text { tendinopathy }\end{array}$ & $\begin{array}{l}\text { Patellofemoral } \\
\text { syndrome }\end{array}$ \\
\hline Athletics & $36 \%$ & $12 \%$ & $4 \%$ & $20 \%$ & $4 \%$ \\
\hline Ballet/dance & $18 \%$ & $9 \%$ & $24 \%$ & $36 \%$ & $0 \%$ \\
\hline Baseball & $33 \%$ & $0 \%$ & $0 \%$ & $0 \%$ & $0 \%$ \\
\hline Basketball & $27 \%$ & $36 \%$ & $0 \%$ & $13 \%$ & $0 \%$ \\
\hline Boxing & $0 \%$ & $33 \%$ & $33 \%$ & $0 \%$ & $33 \%$ \\
\hline Capoeira & $33 \%$ & $33 \%$ & $0 \%$ & $22 \%$ & $0 \%$ \\
\hline Karate & $50 \%$ & $25 \%$ & $0,00 \%$ & $0 \%$ & $0 \%$ \\
\hline Biking & $0 \%$ & $25 \%$ & $0 \%$ & $0 \%$ & $50 \%$ \\
\hline Street run & $23 \%$ & $10 \%$ & $3 \%$ & $10 \%$ & $18 \%$ \\
\hline Climbing & $33 \%$ & $0 \%$ & $0 \%$ & $33 \%$ & $33 \%$ \\
\hline Football & $15 \%$ & $54,5 \%$ & $4 \%$ & $5 \%$ & $3,5 \%$ \\
\hline Gymnastics & $0 \%$ & $0 \%$ & $25 \%$ & $0 \%$ & $25 \%$ \\
\hline Handball & $5 \%$ & $47 \%$ & $5 \%$ & $23 \%$ & $11 \%$ \\
\hline Hapkido & $0 \%$ & $100 \%$ & $0 \%$ & $0 \%$ & $0 \%$ \\
\hline Jiu-jitsu & $24 \%$ & $47 \%$ & $0 \%$ & $14 \%$ & $0 \%$ \\
\hline Judo & $23 \%$ & $35 \%$ & $17 \%$ & $0 \%$ & $6 \%$ \\
\hline Kickboxing & $0 \%$ & $66 \%$ & $0 \%$ & $0 \%$ & $0 \%$ \\
\hline Kung fu & $0 \%$ & $0 \%$ & $25 \%$ & $50 \%$ & $25 \%$ \\
\hline $\begin{array}{l}\text { Greco-Roman } \\
\text { wrestling }\end{array}$ & $0 \%$ & $0 \%$ & $50 \%$ & $0 \%$ & $25 \%$ \\
\hline Motobiking & $0 \%$ & $100 \%$ & $0 \%$ & $0 \%$ & $0 \%$ \\
\hline Bodybuilding & $0 \%$ & $0 \%$ & $0 \%$ & $0 \%$ & $50 \%$ \\
\hline $\begin{array}{l}\text { Synchronized } \\
\text { swimming }\end{array}$ & $0 \%$ & $0 \%$ & $0 \%$ & $0 \%$ & $0 \%$ \\
\hline Swimming & $12,5 \%$ & $12,50 \%$ & $0 \%$ & $12,5 \%$ & $12,5 \%$ \\
\hline Skating & $100 \%$ & $0 \%$ & $0 \%$ & $0 \%$ & $0 \%$ \\
\hline Rowing & $0 \%$ & $0 \%$ & $100 \%$ & $0 \%$ & $0 \%$ \\
\hline Rodeo & $0 \%$ & $100 \%$ & $0 \%$ & $0 \%$ & $0 \%$ \\
\hline Skate & $0 \%$ & $66 \%$ & $0 \%$ & $11 \%$ & $0 \%$ \\
\hline Surf & $66 \%$ & $33 \%$ & $0 \%$ & $0 \%$ & $0 \%$ \\
\hline Taekwondo & $16 \%$ & $33 \%$ & $0 \%$ & $33 \%$ & $0 \%$ \\
\hline Tennis & $0 \%$ & $0 \%$ & $0 \%$ & $0 \%$ & $20 \%$ \\
\hline Table tennis & $0 \%$ & $0 \%$ & $0 \%$ & $100 \%$ & $0 \%$ \\
\hline Triathlon & $0 \%$ & $20 \%$ & $20 \%$ & $0 \%$ & $60 \%$ \\
\hline Volleyball & $15 \%$ & $27 \%$ & $7 \%$ & $30 \%$ & $11 \%$ \\
\hline
\end{tabular}


Table 2. Category versus number of patients/distribution gender/mean age.

\begin{tabular}{|c|c|c|c|}
\hline $\begin{array}{l}\text { Sports } \\
\text { category }\end{array}$ & $\begin{array}{l}\text { Total number } \\
\text { of patients }\end{array}$ & Fem $/$ male $\%$ & Mean age \\
\hline Athletics & 25 & $52 / 48$ & 36 \\
\hline Ballet/dance & 11 & $81 / 19$ & 28,9 \\
\hline Baseball & 4 & $0 / 100$ & 21,7 \\
\hline Basketball & 22 & $32 / 68$ & 25,8 \\
\hline Boxing & 3 & $0 / 100$ & 33 \\
\hline Capoeira & 9 & $23 / 77$ & 29,3 \\
\hline Karate & 8 & $25 / 75$ & 33,5 \\
\hline Biking & 4 & $25 / 75$ & 29,7 \\
\hline Street run & 38 & $31 / 69$ & 42,8 \\
\hline Climbing & 3 & $0 / 100$ & 31 \\
\hline Football & 167 & $17 / 83$ & 28,7 \\
\hline Gymnastics & 4 & $75 / 25$ & 13,75 \\
\hline Handball & 17 & $47 / 53$ & 23,7 \\
\hline Hapkido & 1 & $0 / 100$ & 23 \\
\hline Jiu-jitsu & 21 & $9,5 / 90,5$ & 27,6 \\
\hline Judo & 17 & $35 / 65$ & 21,5 \\
\hline Kickboxing & 3 & $33 / 66$ & 31 \\
\hline Kung-fu & 4 & $50 / 50$ & 28,2 \\
\hline Greco-roman wrestling & 4 & $50 / 50$ & 18,5 \\
\hline Motobiking & 1 & $100 / 0$ & 27 \\
\hline Bodybuilding & 4 & $50 / 50$ & 29,75 \\
\hline $\begin{array}{l}\text { Synchronized } \\
\text { swimming }\end{array}$ & 1 & $100 / 0$ & 23 \\
\hline Swimming & 8 & $25 / 75$ & 34,5 \\
\hline Skating & 1 & $100 / 0$ & 18 \\
\hline Rowing & 1 & $100 / 0$ & 26 \\
\hline Rodeo & 1 & $0 / 100$ & 32 \\
\hline Skate & 9 & $0 / 100$ & 29 \\
\hline Surf & 6 & $17 / 83$ & 30,1 \\
\hline Taekwondo & 6 & $50 / 50$ & 32 \\
\hline Tennis & 5 & $60 / 40$ & 47,4 \\
\hline Table tennis & 1 & $0 / 100$ & 22 \\
\hline Triathlon & 5 & $20 / 80$ & 26,8 \\
\hline Volleyball & 26 & $54 / 46$ & 27,1 \\
\hline
\end{tabular}

$6.2 \%$ were associated with chondral injury and $3.7 \%$ associated with patellar tendinopathy. We still observed a case of association of patellar tendinopathy and patellofemoral syndrome, and one case of posterior cruciate ligament injury associated with posterolateral corner injury (16\%).

In football, the most prevalent sport category, we obtained the distribution of lesions observed in Figure 2.

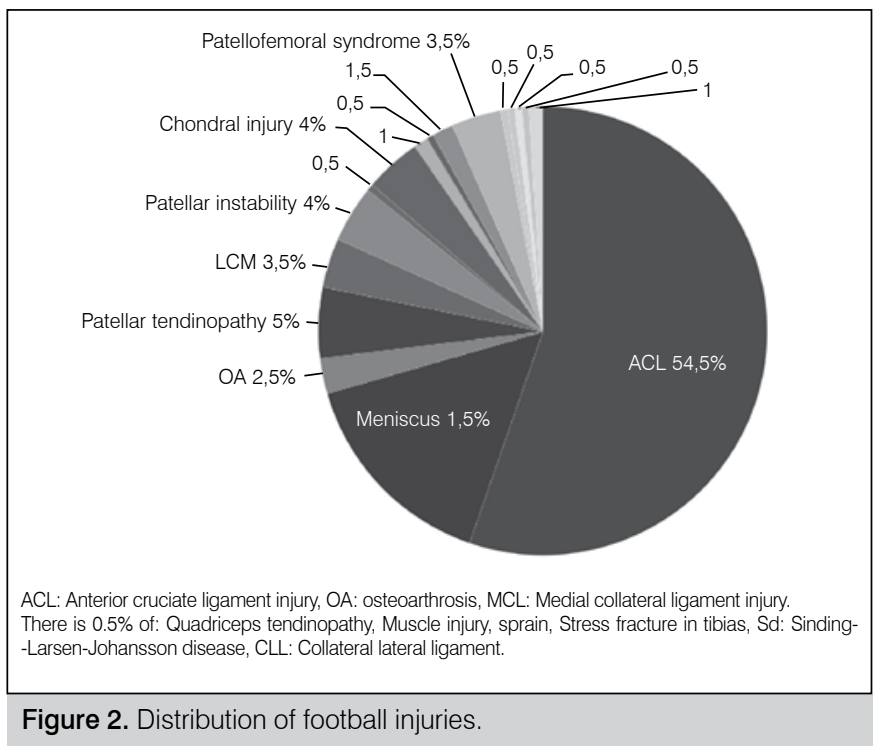

After this initial observational analysis, categories with less than 10 practitioners were excluded because they have no statistical relevance and compared the remaining nine categories by age, gender and most prevalent injuries. The compared categories were: athletics, ballet/dance, basketball, street run, football, handball, jiu-jitsu, judo and volleyball.

In Table 3 we can see the analysis in the categories studied regarding to age.

Through variance analysis with one factor we observed that the groups differ with respect to age ( $p<0.001)$.

According to Bonferroni test, we observed that the street run group differs from the other groups, except the athletic group $(p<0.05)$. The street run group's mean age is significantly higher than other age groups, except for the athletic group.

The athletes group differs from football, volleyball, basketball, handball and judo groups, and presents mean age higher than these groups (Bonferroni test $p<0.05$ ).

The results of comparison of groups regarding to gender are shown in Table 4. Using the chi-square test, we conclude that groups differ regarding gender. The ballet group has the highest percentage of female cases, followed by athletics, handball and volleyball groups.

\begin{tabular}{c|c|c|c}
\multicolumn{5}{c}{ Table 3. Sports category versus age. } \\
\hline & Number & Mean & Median \\
\hline Athletics & 25 & 36,72 & 40 \\
\hline Ballet/dance & 11 & 30,9 & 24 \\
\hline Basketball & 22 & 25,86 & 22,5 \\
\hline Street run & 38 & 42,89 & 43,5 \\
\hline Football & 167 & 28,71 & 27 \\
\hline Handball & 17 & 23,7 & 23 \\
\hline Jiu-jitsu & 21 & 29,66 & 30 \\
\hline Judo & 17 & 21,58 & 20 \\
\hline Volleyball & 26 & 27,15 & 24
\end{tabular}


Table 4. Sports category versus gender.

\begin{tabular}{c|c|c}
\hline & \% fem & $\%$ male \\
\hline Athletics & 52 & 48 \\
\hline Ballet/dance & 81,82 & 18,18 \\
\hline Basketball & 31,82 & 68,18 \\
\hline Street run & 31,58 & 68,42 \\
\hline Football & 16,17 & 83,83 \\
\hline Handball & 47,06 & 52,94 \\
\hline Jiu-jitsu & 9,52 & 90,48 \\
\hline Judo & 35,29 & 64,71 \\
\hline Volleyball & 46,15 & 53,85 \\
\hline
\end{tabular}

And finally, distribution results on the incidence of injuries in the categories we have studied are shown in Table 5.

According to the chi-square test, groups did not differ regarding meniscal injury.

Also according to the chi-square test, (0.001) groups differ regarding $A C L$.

We observe that the football, handball and jiu-jitsu groups have approximately $50 \%$ of cases with ACL. Athletics, ballet and street run represent nearly $10 \%$ of cases with ACL.

According to Fisher's exact test $(<0.001)$, groups differ regarding patellar tendinopathy. Volleyball and ballet groups present the highest percentages. Football and judo, instead, present the smallest percentages.

Also according to Fisher's exact test $(=0.031)$, groups differ with respect to patellar instability. Judo and ballet groups show the highest percentages.

Table 5. Sports category versus diagnoses.

\begin{tabular}{c|c|c|c|c}
\hline & $\begin{array}{c}\text { Meniscal } \\
\text { injury }\end{array}$ & ACL & $\begin{array}{c}\text { Patellar } \\
\text { tendinopathy }\end{array}$ & $\begin{array}{c}\text { Patellar } \\
\text { instability }\end{array}$ \\
\hline Athletics & $36 \%$ & $12 \%$ & $20 \%$ & $4 \%$ \\
\hline Ballet/dance & $18,18 \%$ & $9,09 \%$ & $36,36 \%$ & $27,27 \%$ \\
\hline Basketball & $27,27 \%$ & $36,36 \%$ & $13,64 \%$ & $0 \%$ \\
\hline Street run & $23,68 \%$ & $10,53 \%$ & $10,53 \%$ & $2,63 \%$ \\
\hline Football & $14,97 \%$ & $54,49 \%$ & $4,79 \%$ & $4,19 \%$ \\
\hline Handball & $5,88 \%$ & $47,06 \%$ & $23,53 \%$ & $5,88 \%$ \\
\hline Jiu-jitsu & $23,81 \%$ & $47,62 \%$ & $14,29 \%$ & $0 \%$ \\
\hline Judo & $23,53 \%$ & $35,29 \%$ & $0 \%$ & $17,65 \%$ \\
\hline Volleyball & $15,38 \%$ & $26,92 \%$ & $30,77 \%$ & $7,69 \%$ \\
\hline & & & &
\end{tabular}

\section{DISCUSSION}

In our study the most frequent injuries were meniscal and anterior cruciate ligament injury. These findings corroborate other studies in trauma centers specialized in the sports/knee and injuries most commonly found in sports such as bruises, muscle injuries and tendinopathy eventually appear most frequently in training centers ambulatory and emergency rooms. ${ }^{13,17}$

Another data analyzed was distribution of sports categories: the most prevalent ones were sports with impact and burden of the lower limbs in agreement with other works. ${ }^{8,14,23}$ Football was the most commonly found sport, reflecting Brazilian's profile, in which this sports' culture is prevailing, that besides the intense burden and change towards lower limbs, it is often practiced without technical/medical supervision and in inappropriate floor. The most common found injuries among football practitioners is complete rupture of the anterior cruciate ligament, with $54 \%$ of injuries. The most commonly described injury mechanism is a combination of valgus force on the knee associated with femoral internal rotation/external tibia rotation, which is usually used during a football match. ${ }^{22,24}$ Of this total, $34 \%$ are associated to meniscal injury, similar to data from other services. ${ }^{22,25}$ The second most frequent injury among football practitioners is meniscal injury.

The second most popular sport among the patients analyzed is street run, which is becoming increasingly popular in our midst. As in football, running is most often practiced without technical and/or medical supervision. Unlike football, where torsional mechanisms are common, they rarely occur during run, which explains the low prevalence of ligament injuries. The most common injuries are meniscal lesions, often degenerative (mean age is notoriously higher in this group).

Some lesions found practically independent of the sports category practiced, and are epidemiologically determined by patient's age group. As found in this study, osteochondritis of the tibial tuberosity (Osgood-Schlatter), in which all patients who presented with symptoms and clinical and radiographic signs consistent with the disease, were aged between 10 and 15 years old, as reported in the literature. ${ }^{26}$ Another example would the occurrence of osteoarthritis in patients aged over 55 years old. Among the categories, martial arts showed a high prevalence of ACL injury among those with body contact involving key engines (crashes) such as judo, jiu-jitsu, and those with kicking motion as tae kwon do, kickboxing, and karate in which hyperextension of the knee occurs.

It is noted that the importance of patellar tendinopathy in jumping sports: volleyball (30\%), athletics (20\%), ballet/dance (36\%), handball (23\%), ${ }^{23}$ and patellofemoral syndrome (chondral lesion) in sports with overload on this joint, usually with sports great knee flexion: cycling (50\%), bodybuilding (50\%), and triathlon (50\%). ${ }^{27}$ Regarding gender, a higher rate of female patients was found with a diagnosis of patellofemoral instability. ${ }^{8,14,28}$ This difference between genders was not significant due to the small number of patients with this condition.

Despite some categories are underrepresented in our analysis, it was not possible to establish which injuries may be related to them; others, such as football, street run, volleyball, basketball, athletics, handball, jiu-jitsu, judo and dance (these from the most popular sports in our midst) showed a significant amount of athletes and enables us to establish the epidemiology of knee injuries in these modalities.

The high prevalence of ACL injury in football, handball and jujitsu was statistically significant, as it was patellofemoral instability in dance/ballet and judo (perhaps the highest percentage of female athletes), and patellar tendinopathy in volleyball and ballet. Still regarding the statistical analysis, we found that athletics practitioners were older than and street run and a greater participation of female athletes in ballet/ dance, athletics, handball and dance.

As a weak point of our study, we can mention the small sample 
size in some categories; determining different training conditions for the same category; time of injury until the visit to a specialized center and clarify the mechanism of injury in some categories. In order to overcome this limitation, we suggest multicenter studies with a larger number of patients and longer follow-up.

\section{CONCLUSION}

Our study was relevant to observe large number of patients in sports categories such as football and street run with, respectively, higher rate of injuries to the anterior cruciate ligament and meniscus.

\section{REFERENCES}

1. Pochini AC, Ingham SJM, Oliveira DA, Ejnisman B, Cohen M. Lesões Musculares. In: Cohen M. Guia de Medicina do Esporte-Barueri,SP: Manole; 2008. p.571-9.

2. Teitz CC, Hu SS, Arendt EA. The Female Athlete: Evaluation and Treatment of Sports-Related Problems. J Am Acad Orthop Surg. 1997;5(2):87-96.

3. Patel DR, Luckstead EF, Greydanus DE. Sports injuries. In: Greydanus DE, Patel DR, Pratt HD, editors. Essential adolescent medicine. New York: McGraw-Hill; 2006. p.677-92.

4. Rice SG. Risks of injury during sports participation. In: Sullivan JA, Anderson SJ, editors. Care of the young athlete. Elk Grove Village (IL): American Academy of Orthopaedic Surgeons and American Academy of Pediatrics; 2000. p.9-18.

5. Hergenroeder AC. Prevention of sports injuries. Pediatrics. 1998;101(6):1057-63.

6. Backx FJG. Epidemiology of paediatric sports-related injuries.. In: Bar-Or O, editor. The child and adolescent athlete. Oxford (UK): Blackwell Science; 1996. p.163.

7. Leadbetter WB. Sports injuries. In: Fu F, Stone D, editors. Soft tissue athletic injury. Baltimore: Williams \& Wilkins; 1994. p.733-80.

8. Patel DR, Baker RJ. Musculoskeletal injuries in sports. Prim Care. 2006;33(2):545-79.

9. Whitman PA, Melvin M, Nicholas JA. Common problems seen in a metropolitan sports injury clinic. Phys Sportsmed. 1981;9:105-10.

10. Garrick JG, Requa RK. The epidemiology of foot and ankle injuries in sports. Clin Sports Med. 1988;7(1):29-36.

11. Vital R, Silva HGPV, Sousa RPA, Nascimento RB, Rocha EA, Miranda HF. Lesões traumato-ortopédicas nos atletas paraolímpicos. Rev Bras Med Esporte. 2007;13(3):165-8.

12. McKeag DB. Epidemiology of athletic injuries. In: Primary care sports medicine. Dubuque (IA): Benchmark Press; 1993. p. 63.

13. Brophy RH, Barnes R, Rodeo SA, Warren RF. Prevalence of musculoskeletal disorders at the NFL Combine--trends from 1987 to 2000. Med Sci Sports Exerc.2007;39(1):22-7.

14. Auvinen JP, Tammelin TH, Taimela SP, Zitting PJ, Mutanen PO et al. Musculoskeletal pains in relation to different sport and exercise activities in youth. Med Sci Sports Exerc. 2008;40(11):1890-900.
15. Henke, T.Heck, H. Sports injuries: Epidemiology and prevention strategies in different stages of life. Br J Sports Med.2005;39(6):373-408.

16. Knowles SB, Marshall SW, Guskiewicz KM. Issues in estimating risks and rates in sports injury research. J Athl Train. 2006;41(2):207-15.

17. Feeley BT, Kennelly S, Barnes RP, Muller MS, Kelly BT, Rodeo SA et al. Epidemiology of National Football League training camp injuries from 1998 to 2007. Am J Sports Med. 2008;36(8):1597-603.

18. Rauh MJ, Macera CA, Ji M, Wiksten DL. Subsequent injury patterns in girls' high school sports. J Athl Train. 2007:42(4):486-94.

19. Ingram JG, Fields SK, Yard EE, Comstock RD. Epidemiology of knee injuries among boys and girls in US high school athletics. Am J Sports Med. 2008;36(6):1116-22.

20. Schick DM, Molloy MG, Wiley JP. Injuries during the 2006 Women's Rugby World Cup. Br J Sports Med. 2008;42(6):447-51.

21. Collins CL, Micheli LJ, Yard EE, Comstock RD. Injuries sustained by high school rugby players in the United States, 2005-2006. Arch Pediatr Adolesc Med. 2008;162(1):49-54.

22. Prodromos CC, Han Y, Rogowski J, Joyce B, Shi K. A meta-analysis of the incidence of anterior cruciate ligament tears as a function of gender, sport, and a knee injury-reduction regimen. Arthroscopy. 2007;23(12):1320-1325.e6.

23. Curwin S, Stanish WD. Tendinitis: its etiology and treatment. Lexington, MA Collamara Press; 1984

24. Miller RH. Lesões do Joelho. In: Canale ST. Cirurgia ortopédica de Campbell. 10a. ed. Barueri, SP: Manole; 2007. p. 2165-337.

25. Boden BP, Feagin JA Jr. Natural history of the ACL-deficient knee. Sports Med Arthrosc Rev. 1997;65:20,

26. Nowinski RJ, Mehlman CT. Hyphenated history: Osgood-Schlatter disease. Am J Orthop (Belle Mead NJ). 1998;27(8):584-5.

27. Hughston JC, Walsh WM. Proximal and distal reconstruction of the extensor mechanism for patellar subluxation. Clin Orthop Relat Res. 1979;(144):36-42.

28. White BJ, Sherman OH. Patellofemoral instability. Bull NYU Hosp Jt Dis. 2009;67(1):22-9 